\title{
Ambulatory Medication Reconciliation in Dialysis Patients: Benefits and Community Practitioners' Perspectives
}

\author{
Jo-Anne S Wilson, Matthew A Ladda, Jaclyn Tran, Marsha Wood, Penelope Poyah, Steven Soroka, \\ Glenn Rodrigues, and Karthik Tennankore
}

\begin{abstract}
Background: Ambulatory medication reconciliation can reduce the frequency of medication discrepancies and may also reduce adverse drug events. Patients receiving dialysis are at high risk for medication discrepancies because they typically have multiple comorbid conditions, are taking many medications, and are receiving care from many practitioners. Little is known about the potential benefits of ambulatory medication reconciliation for these patients.
\end{abstract}

Objectives: To determine the number, type, and potential level of harm associated with medication discrepancies identified through ambulatory medication reconciliation and to ascertain the views of community pharmacists and family physicians about this service.

Methods: This retrospective cohort study involved patients initiating hemodialysis who received ambulatory medication reconciliation in a hospital renal program over the period July 2014 to July 2016. Discrepancies identified on the medication reconciliation forms for study patients were extracted and categorized by discrepancy type and potential level of harm. The level of harm was determined independently by a pharmacist and a nurse practitioner using a defined scoring system. In the event of disagreement, a nephrologist determined the final score. Surveys were sent to 52 community pharmacists and 44 family physicians involved in the care of study patients to collect their opinions and perspectives on ambulatory medication reconciliation.

Results: Ambulatory medication reconciliation was conducted 296 times for a total of 147 hemodialysis patients. The mean number of discrepancies identified per patient was 1.31 (standard deviation 2.00). Overall, $30 \%$ of these discrepancies were deemed to have the potential to cause moderate to severe patient discomfort or clinical deterioration. Survey results indicated that community practitioners found ambulatory medication reconciliation valuable for providing quality care to dialysis patients.

Conclusions: This study has provided evidence that ambulatory medication reconciliation can increase patient safety and potentially prevent adverse events associated with medication discrepancies.

Keywords: medication reconciliation, hemodialysis, adverse drug events, medication discrepancies, survey, medication safety

Can J Hosp Pharm. 2017;70(6):443-9

\section{RÉSUMÉ}

Contexte : Le bilan comparatif des médicaments en soins ambulatoires peut réduire les divergences au chapitre des médicaments et les événements indésirables liés aux médicaments. Les divergences relatives aux médicaments représentent un risque élevé pour les patients dialysés, car ils souffrent normalement de multiples troubles comorbides, ils prennent souvent de nombreux médicaments et ils sont soignés par bon nombre de praticiens. Peu d'information existe sur les possibles avantages du bilan comparatif des médicaments en soins ambulatoires pour ces patients.

Objectifs : Déterminer le nombre et la catégorie des divergences concernant les médicaments constatées lors d'un bilan comparatif des médicaments en soins ambulatoires ainsi que la gravité potentielle des préjudices consécutifs. De plus, établir la position des pharmaciens communautaires et des médecins de famille sur cette modalité du bilan comparatif des médicaments.

Méthodes : La présente étude de cohorte rétrospective a été menée auprès de patients amorçant un traitement par hémodialyse pour qui un bilan comparatif des médicaments en soins ambulatoires a été réalisé dans le cadre d'un programme hospitalier des maladies du rein, entre juillet 2014 et juillet 2016. Les divergences trouvées dans les formulaires de bilan comparatif des médicaments ont été classées par catégorie et selon la gravité potentielle des préjudices. Le niveau du préjudice a été déterminé de manière indépendante par un pharmacien et un membre du personnel infirmier praticien à l'aide d'un système de notation défini. En cas de désaccord, le score final était établi par un néphrologue. Des sondages ont été envoyés à 52 pharmaciens communautaires et à 44 médecins de famille prodiguant des soins aux participants afin qu'ils expriment leurs opinions et leurs points de vue sur le bilan comparatif des médicaments en soins ambulatoires.

Résultats : En tout, 296 bilans comparatifs des médicaments en soins ambulatoires ont été effectués auprès de 147 patients hémodialysés. Le nombre moyen de divergences constatées par patient était de 1,31 (écart-type de 2,00). Dans l'ensemble, $30 \%$ de ces divergences ont été considérées comme une source potentielle d'un inconfort allant de modéré à grave ou de dégradation clinique. Selon les résultats du sondage, les praticiens communautaires ont jugé le bilan comparatif des médicaments en soins ambulatoires utile à la prestation de soins de qualité aux patients dialysés.

Conclusions : D'après les résultats de l'étude, le bilan comparatif des médicaments en soins ambulatoires augmenterait la sécurité des patients et pourrait prévenir les événements indésirables liés aux divergences relatives aux médicaments.

Mots clés : bilan comparatif des médicaments, hémodialyse, événements indésirables liés aux médicaments, divergences concernant les médicaments, sondage, sécurité des médicaments 


\section{INTRODUCTION}

M

edication reconciliation in patients with chronic kidney disease has been shown to improve patient safety by allowing identification and resolution of medication-related problems. ${ }^{1-4}$ It is a structured, shared process whereby health care professionals partner with patients and utilize multiple sources of medication information to obtain a best possible medication history (BPMH), to identify and rectify discrepancies, and to communicate this information to the patient and other relevant health care professionals. ${ }^{1}$ The BPMH has been described as a systematic and comprehensive review of all medications that a patient is taking. ${ }^{5}$

Patients who are undergoing hemodialysis are at elevated risk of ongoing medication discrepancies because of their complex medication regimens. On average, these patients are taking 10 to 12 medications per day and 19 pills per day. ${ }^{6-9}$ Because they have many comorbidities, their drug regimens change frequently. It has been reported that an average of 4.7 prescribers are involved in the care of each dialysis patient. ${ }^{10,11}$ These patients also experience a high rate of care transitions, being admitted to hospital on average 1.8 times per year. ${ }^{12}$ In addition, they receive care from dialysis centres, family physicians, specialty care practices, longterm nursing care facilities, community pharmacies, and emergency departments. In one study, $65 \%$ of medication-related problems experienced by patients with end-stage renal disease during hospital admissions occurred as a result of gaps in the transfer of medication information between health care settings and the patients. ${ }^{13}$

As a consequence of these factors, medication-related problems continue to be abundant among patients undergoing hemodialysis. ${ }^{14}$ In a pooled analysis of 7 studies, an average of 4 medication-related problems per patient were identified. ${ }^{15}$ Additionally, drug record discrepancies were identified for $60 \%$ of patients when medical records for outpatients undergoing dialysis were compared with patient surveys. ${ }^{16}$ In previous research involving non-dialysis-dependent patients with chronic kidney disease, our group has shown that ambulatory medication reconciliation is an effective tool for identifying and resolving medication discrepancies. ${ }^{17}$ Data for evaluating the potential level of harm associated with medication discrepancies identified through ambulatory medication reconciliation in hemodialysis patients are limited. Additionally, little is known about the views of members of the community-based health care team about the value of ambulatory medication reconciliation. This study was undertaken to determine the frequency, type, and potential level of harm associated with medication discrepancies identified through ambulatory medication reconciliation in patients undergoing hemodialysis and to ascertain the views of community pharmacists and family physicians about this service.

\section{METHODS}

This retrospective cohort study involved patients initiating hemodialysis in a single hospital-based dialysis unit for whom ambulatory medication reconciliation was conducted from July 2014 to July 2016. The research protocol was approved by the Nova Scotia Health Authority's research ethics board as a noninterventional study. Individual patient consent was not required.

The Nova Scotia Health Authority Central Zone Renal Program provides dialysis to approximately 300 patients daily. Within this program, ambulatory medication reconciliation is a responsibility shared between nurses and pharmacists, who obtain the BPMH and identify medication discrepancies, and prescribers, who reconcile the discrepancies using the reconciliation form (see Appendix 1, available at www.cjhp-online.ca/ index.php/cjhp/issue/view/124/showToc). Once the process has been completed, the form is faxed to the patient's community pharmacy and family physician, a copy is given to the patient, and the form is scanned into the hospital's electronic clinical database. For every patient who initiates hemodialysis, ambulatory medication reconciliation is conducted at the time of initiation and every 6 months thereafter, as well as at transitions in care (e.g., discharge from hospital) as part of routine medical care.

For this retrospective study, centralized electronic health record databases were used to identify eligible patients and reconciliation forms completed during the study period. One investigator (M.A.L.) used charts and the hospital electronic databases to retrieve the following clinical and demographic characteristics: age; sex; ethnicity; cause of end-stage renal disease; Charlson comorbidity index scores; name, dose, route, frequency, and class of each medication; details of any medication discrepancy and action taken (medication continued, discontinued, or changed; referral to original prescriber [i.e., family physician]; or not documented); and medication sources used for the BPMH (patient/family, prescription vials/blister packs, community pharmacy, family physician, long-term care facility, hospital electronic records).

Two investigators (a renal pharmacist [J.T.] and a nurse practitioner [M.W.]) independently classified each medication discrepancy (as identified by nursing and pharmacy staff and recorded on the ambulatory medication reconciliation form) into 1 of 4 four types: drug omission, discrepant dose, discrepant frequency, or incorrect drug. A medication discrepancy was defined as any difference among the information sources used to complete the BPMH. Drug omission was defined as the patient taking a medication that was not listed on at least one of the sources, discrepant dose was defined as a difference in dose between the sources of information, discrepant frequency was defined as a difference in dose frequency between the sources of information, and incorrect drug was defined as a medication prescribed for the patient but not being taken or a drug that the patient was taking but should not have been.

The renal pharmacist and nurse practitioner further independently categorized the medication discrepancies by the potential level of harm or clinical impact as described by the Cornish classification system: class 1 , unlikely to cause patient 
discomfort or clinical deterioration; class 2, potential to cause moderate discomfort or clinical deterioration; and class 3, potential to result in severe discomfort or clinical deterioration. ${ }^{18}$ An example of a class 1 discrepancy would be a patient not taking a phosphate binder such as calcium carbonate, despite the medication being listed on the patient's community pharmacy medication profile. An example of a class 2 discrepancy would be a patient taking cinacalcet twice daily despite the medication frequency being listed as once daily. An example of a class 3 discrepancy would be a patient taking a high daily dose of gabapentin, despite prescription of a substantially lower dose, as documented in the patient's medication records. In the event of disagreement between the 2 investigators in rating the level of harm, the medication discrepancy was referred to a nephrologist (P.P.), who made an independent and final determination of the level of harm.

Fifty-two community pharmacists and 44 family physicians who had received at least one ambulatory medication reconciliation form for a dialysis patient were randomly selected to participate in a short survey to ascertain their views on the clinical value of this process. A letter was sent to these community practitioners in advance of the survey to explain the rationale for the survey and why they had been selected. Anonymous and coded surveys were either mailed or faxed to the participants, who were given 1 month to respond and return the survey by mail or fax. The survey contained 10 questions, most of which were closed-ended questions with an ordinal 5-point response scale (where $5=$ strongly agree, $4=$ agree, $3=$ no strong opinion, $2=$ disagree, and $1=$ strongly disagree).

The primary outcomes were the number and types of medication discrepancies, the number of medication discrepancies resulting in patient discomfort or clinical deterioration according to the Cornish classification system, ${ }^{18}$ and the views of community pharmacists and family physicians about the clinical value of ambulatory medication reconciliation. The secondary outcomes were the classes of medications involved in the discrepancies; the documented action taken when discrepancies were identified (change, continue, discontinue, or refer to original prescriber); and evaluation of the quality of the BPMH using metrics from the Canadian Patient Safety Institute (CPSI) medication reconciliation national audit tool (at least 2 sources of information documented, with patient, family member, or caregiver being identified as 1 of the 2 sources of information; and name, dose, route, and frequency documented for every medication). ${ }^{19}$

Descriptive statistics used to report characteristics of ambulatory medication reconciliation were mean and standard deviation (SD) for continuous data and percentages for ordinal and categorical data. Inter-rater agreement was assessed using both percent agreement and the Cohen kappa statistic. Ordinal data obtained from the closed-ended survey questions were reported as means (and SDs). The $\chi^{2}$ test was used to compare the results of the practitioners' survey responses, and commentaries provided in response to open-ended questions were analyzed for common themes.

\section{RESULTS}

During the study period (July 2014 to July 2016), ambulatory medication reconciliation was conducted a total of 296 times in 147 dialysis patients. Of these, 87 patients (59.2\%) received ambulatory medication reconciliation more than once. The mean patient age was 60 (SD 15) years, and $59.2 \%$ of the patients were men (Table 1). The mean number of medications per patient was 12.7 (SD 4.4).

A total of 193 medication discrepancies were recorded on the reconciliation forms for 70 patients $(47.6 \%$ of the total number of patients). The mean number of medication discrepancies per patient was 1.31 (SD 2.00), and the mean number of discrepancies per ambulatory medication reconciliation was 0.65 (SD 1.16). The types of discrepancies most commonly identified were incorrect drug and discrepant dose (Table 2). A total of 135 medication discrepancies (69.9\%) were classified as unlikely to cause patient discomfort or clinical deterioration (class 1), whereas 50 discrepancies $(25.9 \%)$ were judged likely to cause moderate harm (class 2). Eight discrepancies (4.1\%) were classified as having the potential to cause serious harm (class 3) (Table 2); these medication discrepancies were associated with insulin $(n=4)$, antiepileptic medications $(n=2)$, an antihypertensive $(n=1)$ and an anticoagulant $(n=1)$. There was $96.4 \%$ agreement between the 2 investigators in classifying the type of medication discrepancy, and $72.0 \%$ agreement in classifying the associated level of harm. The Cohen kappa interrater reliability score was 0.942 (95\% confidence interval [CI] $0.895-0.989)$ for categorization of discrepancy type and 0.315 (95\% CI 0.197-0.433) for scoring of level of harm.

\section{Table 1. Patient Demographic Characteristics}

\begin{tabular}{lc} 
Characteristic & $\begin{array}{c}\text { No. (\%) of Participants* } \\
(\boldsymbol{n}=147)\end{array}$ \\
\hline Age (years) (mean \pm SD) & $60 \pm 15$ \\
Sex, male & $87(59.2)$ \\
Ethnicity & \\
$\quad$ White & $130(88.4)$ \\
$\quad$ Black & $9(6.1)$ \\
$\quad$ Other & $8(5.4)$ \\
Cause of ESRD & \\
$\quad$ Diabetes mellitus & $61(41.5)$ \\
$\quad$ Glomerulonephritis & $13(8.8)$ \\
$\quad$ Hypertension & $11(7.5)$ \\
$\quad$ Other & $62(42.2)$ \\
Duration of ESRD (years) (mean \pm SD ) & $1.7 \pm 2.0$ \\
Charlson comorbidity index & $7.34 \pm 0.48$ \\
score (mean \pm SD) & $12.7 \pm 4.4$ \\
No. of medications per patient (mean \pm SD) & \\
\hline SD = standard deviation, ESRD = end-stage renal disease. \\
*Except where indicated otherwise.
\end{tabular}


This single copy is for your personal, non-commercial use only.

For permission to reprint multiple copies or to order presentation-ready copies for distribution, contact CHHP at publications@cshp.ca

Table 2. Types of Medication Discrepancy and Levels of Harm

\begin{tabular}{lrrrrrrrr} 
& \multicolumn{8}{c}{ Level of Harmt; No. (\%) of Discrepanciesł } \\
\cline { 2 - 9 } Discrepancy Type* & \multicolumn{2}{c}{ All Classes } & \multicolumn{2}{c}{ Class 1 } & \multicolumn{2}{c}{ Class 2 } & \multicolumn{2}{c}{ Class 3 } \\
\hline Drug omission & 12 & $(6.2)$ & 9 & $(4.7)$ & 3 & $(1.6)$ & 0 & $(0)$ \\
Discrepant frequency & 36 & $(18.7)$ & 25 & $(13.0)$ & 9 & $(4.7)$ & 2 & $(1.0)$ \\
Discrepant dose & 65 & $(33.7)$ & 44 & $(22.8)$ & 17 & $(8.8)$ & 4 & $(2.1)$ \\
Incorrect drug & 80 & $(41.5)$ & 57 & $(29.5)$ & 21 & $(10.9)$ & 2 & $(1.0)$ \\
Total & 193 & $(100.0)$ & 135 & $(69.9)$ & 50 & $(25.9)$ & 8 & $(4.1)$ \\
\hline
\end{tabular}

*Drug omission = a drug that the patient was taking, but that was not listed in another source; discrepant frequency $=$ a difference in dose frequency between the 2 sources of information; discrepant dose $=a$ difference in dose between the 2 sources of information; incorrect drug = a medication prescribed for the patient but not being taken, or an incorrect drug being taken.

tLevel of harm, according to the Cornish classification system: class $1=$ unlikely to cause patient discomfort or clinical deterioration, class 2 = potential to cause moderate discomfort or clinical deterioration class $3=$ potential to result in severe discomfort or clinical deterioration.

$\neq$ All percentages in the table are based on a denominator of 193 (the total number of discrepancies).

The following classes of medications were associated with medication discrepancies: related to chronic kidney disease (70 [36.3\%]), cardiovascular (35 [18.1\%]), antihyperglycemics (23 [11.9\%]), gastrointestinal (16 [8.3\%]), central nervous system (14 [7.3\%]), respiratory (8 [4.1\%]), and miscellaneous (27 [14.0\%]). When a medication discrepancy was identified, the medication was either discontinued, changed, or referred to the family physician (i.e., the original prescriber) in $72(37.3 \%)$ of cases; in another 39 cases $(20.2 \%)$, the medication was continued, and for the remaining 82 (42.5\%) of discrepancies, no action was documented.

Regarding the CPSI quality metrics of the BPMH, $81.4 \%$ (241/296) of completed ambulatory medication reconciliations had at least 2 sources of medication information for the BPMH (Table 4). Nearly $70 \%$ had the patient, a family member, or a caregiver listed as one of the sources of information. Other sources of medication information used for the BPMH included medication lists generated by a community pharmacy $(n=213)$, prescription vials $(n=156)$, the hospital's electronic health record $(n=13)$, and medication administration records from long-term care facilities $(n=5)$. The name, dose, route, and frequency were documented for $81.1 \%$ of the individual medications included in the BPMHs $(n=3061 / 3774)$. Calcium carbonate and other over-the-counter medications accounted for 34.4\% (245/713) of medications missing one or more of these elements.

Forty-two community practitioners (29 community pharmacists and 13 family physicians) participated in the survey, for an overall response rate of $44 \%$. There was no difference in responses between community pharmacists and family physicians. Most community practitioners (37 [88\%]) reported that they were either very satisfied or satisfied with ambulatory medication reconciliation overall, and $36(86 \%)$ indicated that this process improved the quality of care they provided to their dialysis patients (Figure 1). The respondents agreed or strongly agreed that they valued the documented details of the medication discrepancies (36 [86\%]), the rationale for medication changes or discontinuation (40 [95\%]), and the accuracy of the BPMH (34 [81\%]) on

\section{Table 3. Documented Action Taken for Medication Discrepancies}

\begin{tabular}{lcc} 
Action Taken & No. (\%) of Discrepancies \\
& \multicolumn{3}{c}{$(\boldsymbol{n}=\mathbf{1 9 3 )}$} \\
\hline Change medication & 16 & $(8.3)$ \\
Discontinue medication & 20 & $(10.4)$ \\
Refer to original prescriber & 36 & $(18.7)$ \\
(family physician) & & \\
Continue medication & 39 & $(20.2)$ \\
No action documented & 82 & $(42.5)$ \\
\hline
\end{tabular}

Table 4. Metrics of the CPSI Medication Reconciliation National Audit Tool

\begin{tabular}{lc} 
Metric & No. (\%) \\
\hline $\begin{array}{l}\text { Patient, family member, or caregiver as } \\
\text { one of the sources of information }\end{array}$ & $204 / 296(68.9)$ \\
$\begin{array}{l}\text { At least } 2 \text { sources of information } \\
\text { used to obtain BPMH }\end{array}$ & $241 / 296(81.4)$ \\
$\begin{array}{l}\text { Every medication has a name, dose, } \\
\text { route, and frequency }\end{array}$ & $3061 / 3774(81.1)$ \\
\hline BPMH = best possible medication history, & \\
CPSI = Canadian Patient Safety Institute. &
\end{tabular}

the reconciliation form. Common themes identified in the free-text responses regarding the benefits of ambulatory medication reconciliation were enhanced patient safety, saving of time required to care for dialysis patients as a result of having an accurate up-to-date medication list, and improved continuity of care through being informed of any recent changes in patients' medication regimens. Community practitioners identified legibility of handwriting as an area for potential improvement; they also reported that some sections of the form were incomplete for some patients (e.g., allergy section or section for documenting action taken when a medication discrepancy was identified).

\section{DISCUSSION}

Maintaining an accurate medication list for patients undergoing hemodialysis is challenging, given the high pill burden, 


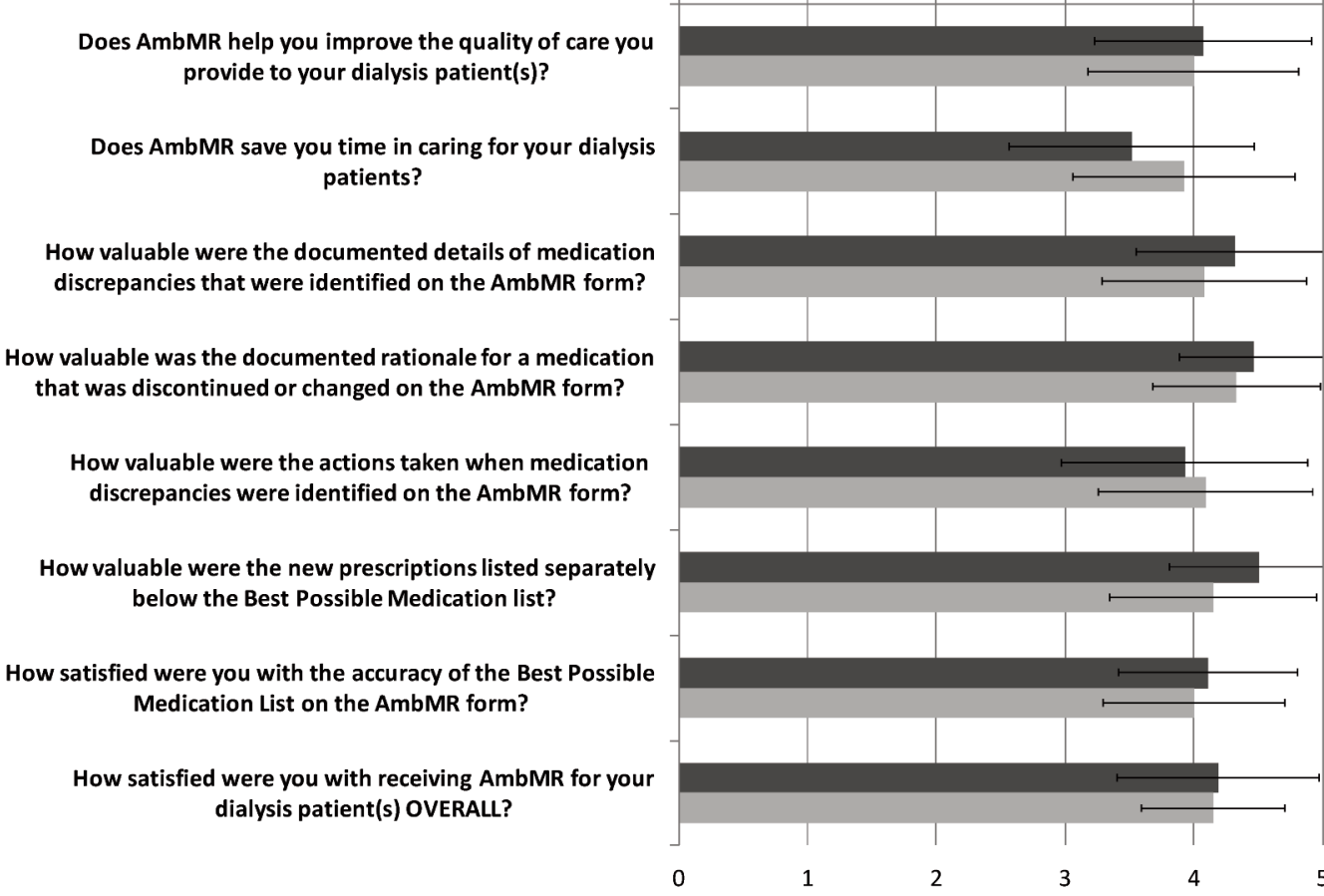

- Community Pharmacists Family Physicians

Figure 1. Responses in a survey of family physicians and community pharmacists concerning ambulatory medication reconciliation (AmbMR). The response to each item is displayed as mean \pm standard deviation, where $5=$ strongly agree, $4=$ agree, $3=$ no strong opinion, 2 = disagree, and $1=$ strongly disagree.

the frequency of medication changes, the presence of multiple comorbidities necessitating involvement of several prescribers, and the frequent care transitions that these patients experience. Several studies have shown that dialysis-dependent patients are at an especially elevated risk of medication-related problems, medication discrepancies, and drug-record discrepancies. ${ }^{3,4,6,7,15,16,20-23}$

In the current 2-year study, the mean number of medication discrepancies identified through ambulatory medication reconciliation was 1.31 per hemodialysis patient and 0.65 per reconciliation process. A previous study reported drug record discrepancies of 1.7 (SD 1.3) per patient when information gathered from the patient was compared with information in an electronic medical record. ${ }^{16}$ Two other Canadian studies, each conducted over a 4-month period, revealed 3.4 and 3.8 medication discrepancies per hemodialysis patient, respectively, when the BPMH was obtained by a pharmacy technician, pharmacy student, or nurse. ${ }^{4,22}$ It is possible that the average number of medication discrepancies was somewhat lower in our study because, for patients with multiple ambulatory medication reconciliations, discrepancies identified during the patient's first reconciliation were resolved, lowering the number of discrepancies on subsequent reconciliations conducted during the 2-year study period. In addition, ambulatory medication reconciliation was new to our renal program, and there was a learning curve for the first several months of the study period.
The most common types of discrepancies identified in this study were incorrect drug (medication prescribed for the patient but not being taken, or the patient was taking the wrong drug) and discrepant dose (difference in dose between sources of information used for the BPMH). These results are consistent with previous studies, which reported that the most common types of discrepancies were associated with patients no longer taking the prescribed medication or dose discrepancies. ${ }^{4,15,16,22}$ Although we did not measure adherence, several reports have shown that hemodialysis patients are frequently non-adherent with their prescribed regimen. ${ }^{23,24}$ This is not surprising, given the number of medications prescribed for these patients. Medications related to chronic kidney disease accounted for the most common drug class associated with medication discrepancies (36.3\%). Because many of these medications require frequent laboratory monitoring and subsequent dose adjustments (e.g., erythropoietin, iron, vitamin $\mathrm{D}$ analogue, phosphate binders, antihypertensives), it is imperative that patients are informed about and understand the changes to their medication regimens. This finding informed our program that both renal health care providers and patients require additional education to reduce discrepancies for medications related to chronic kidney disease.

Overall, $30 \%$ of the medication discrepancies identified in this study were deemed to have the potential to cause moderate $(25.9 \%)$ or severe $(4.1 \%)$ patient discomfort or clinical 
deterioration. Discrepancies associated with prediction of moderate or severe harm were diverse in nature, ranging from patients taking more or less medication than the prescribed amount to not taking a prescribed medication at all. In this study, the level of harm was independently classified by 2 investigators (a pharmacist and a nurse practitioner), and in the event of disagreement a third investigator (a nephrologist) made the final determination. In 2 other studies, the personnel rating the level of harm were not blinded, and ratings were conducted either by a consensus group or by a single investigator. ${ }^{4,22}$ These studies reported $1 \%$ and $6 \%$ of medication discrepancies, respectively, as clinically significant potential adverse drug events. One of the studies $^{22}$ employed the same classification system for rating potential level of harm as we did, whereas the other study investigators categorized the potential for medication discrepancies to cause patient harm as "unlikely", "possible", or "probable". ${ }^{4}$ In a previous study by our team in non-dialysis-dependent patients with stage 5 chronic kidney disease, 36\% of medication discrepancies identified through ambulatory medication reconciliation were rated as having the potential to cause either moderate or severe patient harm. ${ }^{17}$ Providing ambulatory medication reconciliation is critically important to reducing the risk of harm associated with medication discrepancies, such as adverse drug events and admission to hospital. ${ }^{3}$

The majority of survey respondents reported that ambulatory medication reconciliation improved the quality of care that practitioners provided to their dialysis patients. As part of our process, a copy of each patient's reconciliation form is sent to the patient and to the relevant community pharmacy and family physician. More than $80 \%$ of community practitioners found that the BPMH obtained during ambulatory medication reconciliation was accurate, reported that it reduced the time needed to care for their dialysis patients, and found the details of the documented medication discrepancies valuable. Additional training for the health care professionals responsible for completing the reconciliation form, improvement of handwriting legibility, and implementation of an electronic system allowing for the transfer of medication information to community pharmacists and family physicians during transitions of care were identified as possible ways to improve the process and reduce medication discrepancies in this patient population. The common themes noted in responses to our survey regarding the benefits and challenges of ambulatory medication reconciliation were similar to those reported in previous studies of community pharmacist and family physician perspectives on medication reconciliation. ${ }^{25,26}$

This study had several limitations. First, only 42 (44\%) of the invited community practitioners participated in the survey, which represents a small cross-section of clinicians. Second, this study was conducted at a hospital-based hemodialysis site, as opposed to a non-hospital-based site; as such, the patients may have had more complex medication regimens than would be seen in non-hospital settings. Third the evaluation of discrepancy type and potential for harm were performed retrospectively, which meant that investigators had to base their determinations solely on the details documented on the ambulatory medication reconciliation form. Fourth, when medication discrepancies were identified, an action plan was documented only $57.5 \%$ of the time. The absence of an action plan for nearly half of the medication discrepancies may have been due to the novelty of the reconciliation process at our site during the study period. Additionally, in-hospital prescribers must send letters to community family physicians when additional follow-up of medication-related problems is required (rather than being able to initiate follow-up themselves). These data inform the need for a more streamlined approach to documentation and further education for health care professionals to ensure a documented follow-up action plan for every medication discrepancy. Finally, because this was a retrospective study, there is uncertainty about any effects of the resolution of documented medication discrepancies on patient outcomes.

This study also had several strengths. Previous studies reported on medication-related problems and drug record discrepancies, whereas we reported on the identification and resolution of medication discrepancies. Although this approach made direct comparisons with the prior literature difficult, reporting on medication discrepancies may be perceived as a strength, because issues identified on ambulatory medication reconciliation could be resolved proactively, rather than reporting on adverse drug events that have already occurred. The quality metrics employed in this study were modelled after existing inpatient medication reconciliation metrics developed by the CPSI. ${ }^{19}$ The ambulatory medication reconciliations completed in this study were deemed to be of high quality, as more than $80 \%$ of the BPMHs were obtained from 2 sources of medication information and name, dose, route, and frequency were documented for more than $80 \%$ of the medications listed. The evaluation of ambulatory medication reconciliation using standardized quality metrics is necessary to ensure that the forms are being completed properly. Lastly, a single researcher collected all of the data for this study, which ensured data consistency, and the 3 investigators scoring level of harm associated with medication discrepancies were blinded to one another's score, which minimized bias.

\section{CONCLUSION}

Regularly performing ambulatory medication reconciliation and including community practitioners in the model of care can improve the quality of health care delivered to patients receiving hemodialysis. This study demonstrated that ambulatory medication reconciliation is an effective tool to identify and resolve medication discrepancies and can potentially mitigate moderate to severe patient discomfort or clinical deterioration in 
dialysis patients. Whether it improves outcomes with respect to morbidity and mortality or reduces the cost of care for this population requires further study.

\section{References}

1. Required organizational practices: handbook 2017. Ottawa (ON): Accreditation Canada; 2016.

2. St Peter WL. Improving medication safety in chronic kidney disease patients on dialysis through medication reconciliation. Adv Chronic Kidney Dis. 2010;17(5):413-9.

3. Pai AB, Cardone KE, Manley HJ, St Peter WL, Shaffer R, Somers M, et al. Medication reconciliation and therapy management in dialysis-dependent patients: need for a systematic approach. Clin J Am Soc Nephrol. 2013; 8(11):1988-99.

4. Chan WWY, Mahalingam G, Richardson RMA, Fernandes OA, Battistella M. A formal medication reconciliation programme in a haemodialysis unit can identify medication discrepancies and potentially prevent adverse drug events. J Ren Care. 2015;41(2):104-9.

5. Medication reconciliation $(\mathrm{MedRec})$. Toronto $(\mathrm{ON})$ : Institute for Safe Medication Practices Canada; [cited 2017 Apr 28]. Available from: www.ismp-canada.org/medrec

6. Kaplan B, Mason NA, Shimp LA, Ascione FJ. Chronic hemodialysis patients. Part I: Characterization and drug-related problems. Ann Pharmacother. 1994:28(3):316-9.

7. Kaplan B, Shimp LA, Mason NA, Ascione FJ. Chronic hemodialysis patients. Part II: Reducing drug-related problems through application of the focused drug therapy review program. Ann Pharmacother. 1994;28(3):320-4.

8. Manley HJ, McClaran ML, Overbay DK, Wright MA, Reid GM, Bender WL, et al. Factors associated with medication-related problems in ambulatory hemodialysis patients. Am J Kidney Dis. 2003;41(2):386-93.

9. Chiu YW, Teitelbaum I, Misra M, de Leon EM, Adzize T, Mehrotra R. Pill burden, adherence, hyperphosphatemia, and quality of life in maintenance dialysis patients. Clin J Am Soc Nephrol. 2009;4(6):1089-96.

10. Rifkin DE, Laws MB, Rao M, Balakrishnan VK, Sarnak MJ, Wilson IB. Medication adherence behavior and priorities among older adults with CKD: a semistructured interview study. Am J Kidney Dis. 2010:56(3):439-46.

11. Manley HJ, Garvin CG, Drayer DK, Reid GM, Bender WL, Neufeld TK, et al. Medication prescribing patterns in ambulatory haemodialysis patients: comparisons of USRDS to a large not-for-profit dialysis provider. Nephrol Dial Transplant. 2004;19(7):1842-8.

12. United States renal data system. 2016 USRDS annual data report: epidemiology of kidney disease in the United States. Bethesda (MD): National Institutes of Health, National Institute of Diabetes and Digestive and Kidney Diseases; 2016.

13. Ong SW, Fernandes OA, Cesta A, Bajcar JM. Drug-related problems on hospital admission: relationship to medication information transfer. Ann Pharmacother. 2006;40(3):408-13.

14. St Peter WL. Management of polypharmacy in dialysis patients. Semin Dial. 2015;28(4):427-32.

15. Manley HJ, Cannella CA, Bailie GR, St Peter WL. Medication-related problems in ambulatory hemodialysis patients: a pooled analysis. Am J Kidney Dis. 2005;46(4):669-80.

16. Manley HJ, Drayer DK, McClaran M, Bender W, Muther RS. Drug record discrepancies in an outpatient electronic medical record: frequency, type, and potential impact on patient care at a hemodialysis center. Pharmacotherapy. 2003;23(2):231-9.

17. Phillips M, Wilson JA, Aly A, Wood M, Poyah P, Drost S, et al. An evaluation of medication reconciliation in an outpatient nephrology clinic. CANNT J. 2016;26(2):29-33.

18. Cornish PL, Knowles SR, Marchesano R, Tam V, Shadowitz S, Juurlink DN, et al. Unintended medication discrepancies at the time of hospital admission. Arch Intern Med. 2005;165(4):424-9.

19. Measures: medication reconciliation (MedRec). Edmonton (AB): Canadian Patient Safety Institute; [cited 2016 Aug 29]. Available from: www. patientsafetyinstitute.ca/en/toolsresources/psm/pages/medrec-measurement. aspx
20. Grabe DW, Low CL, Bailie GR, Eisele G. Evaluation of drug-related problems in an outpatient hemodialysis unit and the impact of a clinical pharmacist. Clin Nephrol. 1997;47(2):117-21.

21. Tang I, Vrahnos D, Hatoum H, Lau A. Effectiveness of clinical pharmacist interventions in a hemodialysis unit. Clin Ther. 1993;15(2):459-64.

22. Leung M, Jung J, Lau W, Kiaii M, Jung B. Best possible medication history for hemodialysis patients obtained by a pharmacy technician. Can J Hosp Pharm. 2009;62(5):386-91.

23. Bleyer AJ, Hylander B, Sudo H, Nomoto Y, de la Torre E, Chen RA, et al. An international study of patient compliance with hemodialysis. JAMA. 1999;281(13):1211-3.

24. Leggat JE Jr, Orzol SM, Hulbert-Shearon TE, Golper TA, Jones CA, Held PJ, et al. Noncompliance in hemodialysis: predictors and survival analysis. Am J Kidney Dis. 1998;32(1):139-45.

25. Kennelty KA, Chewning B, Wise M, Kind A, Roberts T, Kreling D. Barriers and facilitators of medication reconciliation processes for recently discharged patients from community pharmacists' perspectives. Res Social Adm Pharm. 2015;11(4):517-30.

26. Redmond P, Carroll H, Grimes T, Galvin R, McDonnell R, Boland F, et al. GPs' and community pharmacists' opinions on medication management at transitions of care in Ireland. Fam Pract. 2016;33(2):172-8.

Jo-Anne S Wilson, BSCPharm, ACPR, PharmD, is with the College of Pharmacy, Faculty of Health Professions, Dalhousie University, and the Division of Nephrology, Department of Medicine, Nova Scotia Health Authority Renal Program, Central Zone, Halifax, Nova Scotia.

Matthew A Ladda, BScPharm, is with the College of Pharmacy, Faculty of Health Professions, Dalhousie University, Halifax, Nova Scotia.

Jaclyn Tran, BSCPharm, ACPR, is with the Nova Scotia Health Authority Renal Program, Central Zone, Halifax, Nova Scotia.

Marsha Wood, RN, NP, is with the Nova Scotia Health Authority Renal Program, Central Zone, Halifax, Nova Scotia.

Penelope Poyah, MD, FRCPC, is with the Division of Nephrology, Department of Medicine, Nova Scotia Health Authority, and the Division of Nephrology, Faculty of Medicine, Dalhousie University, Halifax, Nova Scotia.

Steven Soroka, MD, MSC, FRCPC, is with the Division of Nephrology, Department of Medicine, Nova Scotia Health Authority, and the Division of Nephrology, Faculty of Medicine, Dalhousie University, Halifax, Nova Scotia.

Glenn Rodrigues, BScPharm, is with the College of Pharmacy, Faculty of Health Professions, Dalhousie University, Halifax, Nova Scotia.

Karthik Tennankore, MD, MSC, SM, FRCPC, is with the Division of Nephrology, Department of Medicine, Nova Scotia Health Authority, and the Division of Nephrology, Faculty of Medicine, Dalhousie University, Halifax, Nova Scotia.

\section{Competing interests: None declared.}

\section{Address correspondence to:}

Dr Jo-Anne Wilson

Division of Nephrology, Department of Medicine

Dalhousie University

Room 5092, Dickson Building

5820 University Avenue

Halifax NS B3H 2 Y9

e-mail: Jo-Anne.Wilson@dal.ca

Funding: This study was supported by a research grant from the Dalhousie University College of Pharmacy Endowment Fund. 